\title{
Candida Diaper Dermatitis
}

National Cancer Institute

\section{Source}

National Cancer Institute. Candida Diaper Dermatitis. NCI Thesaurus. Code C111887.

An inflammatory skin condition in the diaper area superimposed with Candida infection, characterized by a bright red rash with a sharply demarcated edge and satellite lesions. Skin folds are often involved. 